\title{
Protomassificações: 0 início do conceito comunicacional de massificação na Grécia Antiga
}

\section{Rafael Duarte Oliveira Venancio}

\section{Resumo}

0 presente artigo deseja identificar o início do conceito de massificação na Grécia Antiga. A investigação epistemológica-histórica aqui posta busca entender como conceitos tais como hoi polloi e isegoria, em articulações com noções de Retórica e Parrhesia, podem ser demarcados como o início de uma formulação desse conceito-chave dentro das Ciências da Comunicação, antecipando a formulação clássica de massificação posta por Alexis de Tocqueville.

\section{Palavras-Chave}

Epistemologia. Hoi polloi. Massificação.

\section{Rafael Duarte Oliveira Venancio ।}

rdovenancio@gmail.com

Doutor em Meios e Processos Audiovisuais pela Universidade de São Paulo - USP, Brasil. Professor do curso de Jornalismo e do Programa de Pós-Graduação em Tecnologia, Comunicação e Educação e Diretor da Faculdade de Educação da Universidade Federal de Uberlândia - UFU, Brasil.

\section{Introdução}

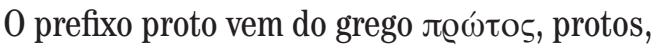
que tem o significado corrente de "primeiro". Esse significado, corrente em diversas línguas, tem sua origem no fato de que ele é o superlativo da palavra grega лoo, pro, que tem o significado corrente de "antes". No entanto, Isidro Pereira (1951, p. 489), em seu afamado Dicionário GregoPortuguês e Português-Grego, indica-nos diversos outros significados e usos da palavra em seu original grego.

Como adjetivo, лొótos pode ser [...] "primeiro, 0 mais dianteiro; primeiro, o mais primitivo; supremos, o mais nobre". No entanto, como substantivo em sua forma no singular, ele possui uma simples designação: "0 começo" [...] (PEREIRA, 1951, p. 489). Claro que não podemos esquecer do uso de proto para identificar um hipotético ancestral, tal é 0 caso do exemplo linguístico da existência de uma língua proto-indo-europeia.

Acreditamos que esses dois últimos significados refletem bem o que designamos nesse artigo por 
"protomassificações". Protomassificações se referem a conceitos muito próximos de massificação e de massa existentes muito antes do nascimento formal desses termos com 0 advento da democracia moderna (i.e. democracia norte-americana em 1776).

Assim não podemos tratá-las como massificações de jure, apenas de facto. Além disso, essa vinculação ao período "pós-Tocqueville", para fazer uma referência àquele que é considerado pai do conceito $0^{1}$ - apesar dele já existir, em formulação, com os federalistas norteamericanos ${ }^{2}$ - pode ser considerada hipotética, fruto do presente trabalho que está imerso na premissa de uma construção de um percurso histórico-discursivo à luz da História das Ideias.

Claro que muitos dos tópicos, que apresentaremos no presente artigo baseado em trabalho anterior ${ }^{3}$ (VENANCIO, 2013), já foram vinculados com antecessores de conceitos de massificações/massa de direito. Um bom exemplo disso, dentro do nosso campo das Ciências da Comunicação, está na famosa construção de Jesús Martin-Barbero (2006, p. 33-53) que traça uma linha ${ }^{4}$ de desenvolvimento que vai do conceito de povo nos Discorsi, de Maquiavel, à maioria/massa de Tocqueville.

Dessa forma, mesmo que não seja original, nossa construção de uma pré-história do conceito de massificação se coloca no vértice dos três elementos básicos para se caracterizar esse conceito como tal: (1) o vislumbre de uma ampla participação sociopolítica/cultural das camadas não pertencentes às elites sociais ou políticas ou culturais; (2) 0 âmbito de uma Comunicação Social, mesmo que seja fundada no presencial e/ou interpessoal; e (3) no contato direto

Para citar apenas uma referência comprovadora dessa instância, podemos nos lembrar da afirmação de Alan Swingewood (1977, p. 3): "Democracia na América (1835-1840), de Alexis de Tocqueville, é normalmente citado como a primeira crítica sociológica da sociedade de massa". Alexis de Tocqueville e Gustave de Beaumont foram enviados pelo governo francês em 1831 para estudarem 0 sistema prisional norte-americano. A estadia durou até 0 ano seguinte, quando retornaram para a França. Além de escreverem o relatório demandado pelo governo do rei Louis-Philippe I, os dois se empenharam em escrever livros acerca das impressões que tiveram na viagem. No caso de Tocqueville, esse livro é o próprio Democracia na América, cujo primeiro volume foi publicado em 1835 e o segundo em 1840. Um dos conceitos-chave presente no livro - e que fazem de Tocqueville o "pai" do conceito - é o da "Tirania da Maioria" (Tyranny of Majority), também traduzido e popularizado como "Tirania das Massas".

Os Federalist Papers foram de grande influência em Tocqueville, tanto que ele cita um longo trecho do Federalista L/ atribuído a James Madison e escrito em 1788, quase 50 anos antes. Nesse ponto do Democracia na América, pertencente à seção que afirma que "o grande perigo das repúblicas americanas vem da onipotência da maioria", a afirmação federalista que se destaca é aquela que diz que "é de grande importância em uma república (...) não só proteger a sociedade contra a opressão de seus governantes, mas proteger uma parte da sociedade contra a injustiça de outra parte", no caso, a maioria (MADISON apud TOCQUEVILLE, 2002, p. 249).

Este trabalho foi desenvolvido com bolsa de apoio da Fundação de Apoio à Pesquisa do Estado de São Paulo (FAPESP).

"A ideia de povo, que gera o movimento romântico, vai sofrer ao longo do século XIX uma dissolução completa: pela esquerda, no conceito de classe social, e pela direita, no de massa" (MARTIN-BARBER0, 2006, p. 41). 
entre as elites mencionadas e as camadas não pertencentes a elas.

Tal construção téorica pode ser definida como uma hipótese que será demonstrada ao longo do presente trabalho. As protomassificações aqui descritas podem não ter nome, mas possuem um funcionamento idêntico.

\section{Hoi polloi e Isegoria}

Parece, de certa forma, redundante contar a história de um conceito a partir dos gregos. Para muitos, é um procedimento de revisão teórica impreciso já que se esquece das também desenvolvidas civilizações orientais do período. No entanto, temos razões para proceder dessa forma.

Nos gregos, mais precisamente nos primórdios da democracia ateniense, é que encontramos, pela primeira vez, o vértice que orienta esse percurso histórico-discursivo, principalmente o primeiro fator: 0 vislumbre de uma ampla participação social. A origem desse movimento está na ascensão de Sólon ao poder.

Considerado o grande antecipador da democracia grega, a Sólon são atribuídas, fato que remota à Antiguidade Clássica, diversas reformas constitucionais, mas a maioria já não são consideradas genuínas atualmente. No entanto, duas reformas principais, datadas de 594 a.C. (século VI a.C.), são vinculadas factualmente ao estadista: a retificação da posição dos atenienses que caíram na servidão por dívidas e uma mudança nos pré-requisitos para assumir os maiores cargos governamentais. Nessas reformas, Sólon usou emendas constitucionais para modificar tanto acerca da filiação da classe dominante como nas relações sociopolíticas entre massa e elite (OBER, 1990, p. 60).

Agora, a definição social de quem era elite - ou melhor dizendo, quem era cidadão ou não estava em critérios econômicos, criando uma elite mais permeável aos novos ricos. Divididos em 4 classes de acordo com a produção agrícola anual - sendo elas, do mais rico ao mais pobre: pentekosiomedimnoi (500 medimnoi de cereais anuais); hippeis (300); zeugitai (200); e thetes (menos de 200). Junto com essa nova estratificação, o cancelamento da servidão por dívida em solo ateniense promoveu maior precarização das classes mais baixas, que não podiam mais vender a sua liberdade para garantir melhores condições de sobrevivência como escravos. Ser escravo, agora, era mais uma questão de nascimento do que - por mais estranho que seja aos nossos ouvidos atuais uma questão de opção.

Como a reforma constitucional de Sólon, que distancia ainda mais a elite das classes mais baixas, seria um prenúncio de democracia e de ampla participação social? Além disso, como promoveria um maior lugar de contato comunicacional em uma situação claramente intransponível?

0 que acontecia na Grécia do século VI a.C. - e que gerava os conflitos sociais que resultaram na 
ascensão de Sólon ao poder - é que existia uma classe intermediária, tal como a nossa classe média, que não pertencia à antiga elite ateniense definida apenas pelo nascimento nobre. Essa é a verdadeira massa de Atenas, identificada por três conceitos gregos: to plēthos, hoi polloi e ho ochlos. Normalmente, eles são traduzidos como "a massa", "os muitos" e "a multidão", respectivamente, e essa 'definição de 'massa' exclui muitas pessoas (escravos, mulheres, nãocidadãos da classe trabalhadora) que seriam incluídas em uma descrição marxista das massas de Atenas" (OBER, 1990, p. 11).

Portanto, esses hoi polloi, com a reforma de Sólon, transformam-se em thetes ou mesmo em zeugitai. É assim que adquirem cidadania e, consequentemente, uma filiação à elite ateniense que toma as decisões da cidade-Estado. Ora, tal como Josiah Ober (1990, p. 63) analisa, "se as massas atenienses caíssem em uma posição de igualdade aos escravos, haveria um perigo manifesto de criar uma classe baixa homogênea. $\mathrm{E}$ se essa ampla classe baixa ficasse consciente de seu poder coletivo, isso significaria o fim da ordem social existente".

Verificamos, aqui, logo no "momento fundador" do conceito de massificação, a presença do primeiro fator que constitui a nossa hipótese acerca do que unificaria todos os conceitos de massificação, ao longo do percurso histórico-discursivo. Vemos aqui um indício de que a construção de uma massa é uma necessidade das elites - financeiras, culturais e/ou produtivas - para se relacionar com aqueles que estão fora de seu círculo de poder (e que podem, por ventura, ameaçá-lo).

Assim, os hoi polloi não poderiam se sentir líderes dos não-cidadãos enquanto cidadãos, thetes. Para completar essa inclusão promovida por Sólon, há a permissão da participação do thetes na Ekklesia (a Assembleia Política) e na Heliaia (o Tribunal do Júri). "Não é claro se Sólon abriu a Assembleia para os thetes (como alguns assumem) ou a deixou aberta. 0 poema de Sólon citado pela Athenaion Politeia sugere que ele não reduziu a posição política dos thetes, mas não diz se a eles foram dados novos direitos políticos" (OBER, 1990, p. 64).

A dúvida aqui colocada por Josiah Ober, refletida por outros estudos contemporâneos da política grega do século VI a.C., está se os thetes podiam participar ou apenas assistir os trabalhos da Ekklesia. A principal fonte dessa informação está na Athenaion Politeia, de Aristóteles, normalmente traduzida como Constituição dos Atenienses. No entanto, não podemos negar que esse princípio de inclusão política de classes médias atenienses - formando assim a primeira "massa" - demonstra a constituição tanto de um vislumbre de uma ampla participação sociopolítica/cultural das camadas não pertencentes às elites sociais ou políticas, ou culturais, quanto à construção de um locus de contato direto entre as elites mencionadas e as camadas não pertencentes a elas. 
Só que a questão de âmbito de uma Comunicação Social - mesmo que seja fundada no presencial e/ou interpessoal-, principalmente, entre elite e massa, não parece resolvida graças à dúvida se thetes eram autorizados a participar das deliberações coletivas do processo sociopolítico ateniense.

A resposta definitiva para isso está no governo do tirano da outra metade do século VI a.C.: Pisístrato. Ora, enquanto sabemos que "a tirania de Pisístrato pode ter sido o fator de amplo crescimento das rivalidades internas da elite, há pouca participação das massas em qualquer um dos seus três golpes" (OBER, 1990, p. 65). Só que, apesar desse fato, seu Governo, estabelecido em 546 a.C. após o terceiro golpe, foi o que mais promoveu algo que poderíamos chamar de primórdios da Comunicação Social, principalmente com as massas.

Pisístrato tentou legitimar sua própria posição ao estimular uma identificação ideológica mais próxima da cidadania como um todo com o Estado ateniense (OBER, 1990, p. 67). Surge algo tal como uma máquina de propaganda - utilizando eventos culturais como a criação do Festival Panathenaico e a organização anual do Festival de Dionísio - que reforçaria as ligações do tirano com o Estado como um todo, criando algo como um culto de personalidade.

Tal "como Sólon, Pisístrato percebeu o poder potencial da integração ideológica do populacho como uma fonte de apoio à ordem existente.
Só que, como uma consequência indireta (...), as massas atenienses ficaram, crescentemente, conscientes de si mesmas" (OBER, 1990, p. 66). A cidadania não era mais uma simples proteção à degradação, ao nivelamento aos escravos estrangeiros, mas sim algo que poderia significar mais politicamente, afinal eram todos - tal como era dito nos eventos culturais da época - atenienses.

Após a morte de Pisístrato, a massa continuou a usufruir politicamente a amplitude da Comunicação Social instaurada anteriormente. Tanto que, para Clístenes se manter no poder, após os conflitos de 510-508 a.C. , precisou observar as vontades dessa maioria (to plēthos) recorrendo para a política do consenso.

Junto com essa isonomia, Clístenes regulamentou a possibilidade do demos como um todo votar acerca das decisões do Estado. Aristóteles (2003, p. 51) chega a afirmar que, "vencido pelas associações políticas, Clístenes pôs-se do lado do povo e concedeu a soberania à multidão [plethos]".

Além disso, há a dúvida se Clístenes introduziu a liberdade de debate - conhecida como isegoria - na Assembleia. Ober (1990, p. 72-3), contrário a essa ideia, afirma que há "uma fraca ligação entre a introdução [da isegoria] por Sólon e a reinstalação por Clístenes. 0 melhor argumento é de Raaflaub que sugere que Clístenes introduziu, ao menos, "a possibilidade do discurso público pelos membros hoplitas [zeugitai] da sociedade" (OBER, 1990, p. 72-3). 
Na contramão de Lewis e Raaflaub, há argumentação de que "a legitimidade da veiculação pública de diferenças de opinião e de divergências implicadas pela isegoria vai diretamente contra 0 espírito consensual da reforma do deme por Clístenes" (OBER, 1990, p. 73). Ora, se todos os cidadãos pensam em termos afins, se todos os indivíduos em comunidade estão em consenso, não há a necessidade de um debate político aberto.

Tendo colocado a isegoria ou não, a isonomia - definida como igualdade de participação na concepção de decisões (leis) que manterão e promoverão igualdade e que tratará todos os cidadãos igualmente - de Clístenes levará à demokratia, consequentemente à isegoria, de Péricles, já no século V antes da era Cristã. Era a consolidação do poder discursivo das massas, iniciado pela introdução do ostracismo por voto no governo de Clístenes, símbolo maior da isonomia. Tal como Josiah Ober (1990, p. 75) descreve, "a prática do ostracismo pode ter tido uma mensagem simbólica subsidiária mais explícita para a cidadania ateniense: nenhum membro da elite, sem importar o quão poderoso ele era, estava livre da ira das massas".

0 ostracismo foi apenas o início, e nas oito décadas entre as reformas de Clístenes e a morte de Péricles (429 a.C.), a maioria dos bastiões institucionais do privilégio político da elite foi desmontado e o poder político coletivo das massas foi aumentado (OBER, 1990, p. 75).
0 período de Péricles é tão significativo para a questão do conceito de massas que, normalmente, o primeiro uso positivo de hoi polloi está na Oração Fúnebre de Péricles, transcrita na História da Guerra do Peloponeso, de Tucídides. A citação é a seguinte:

Nossa constituição não copia as leis dos Estados vizinhos; nós somos antes um padrão para os outros do que imitadores por nós mesmos. Sua administração favorece os muitos [hoi polloi] ao invés dos poucos [hoi oligoi]; é por isso que é chamada de democracia (THUCYDIDES, 2004, p. 83).

Pronunciada entre 431-430 a.C., a Oração

Fúnebre, enunciada por Péricles, encerrava o primeiro ano da participação ateniense na Guerra do Peloponeso. Esse discurso oral "demonstra como o talento persuasivo de Péricles era capaz de manter o apoio dos atenienses à sua penosa estratégia (...). Em seu discurso, ele pintou o retrato mais glorioso e cativante da democracia atensiense que conhecemos" (KAGAN, 2006, p. 105).

\section{Em História da Guerra do Peloponeso, Tucídides} (2004, p. 96) afirma que Péricles "era capaz de exercitar um controle independente sob a multidão - resumindo, liderava-os ao invés de ser deixado liderar por eles (...). 0 que era nominalmente uma democracia, tornou-se em suas mãos um governo pelo seu primeiro cidadão". No entanto, 0 conhecido entusiasmo de Tucídides por Péricles omite as oposições às políticas logo em 431 a.C; além de indicar um desprezo pelas massas - 
tratada por ele como multidão ou turba -, algo que trataremos um pouco mais adiante.

Quando a guerra chegou a cinco quilômetros da Acrópole, na devastação da cidade de Acarnas, o clima de fúria tomou Atenas, tanto acerca dos invasores espartanos como contra Péricles.

0 maior detator era Cléon, que vinha se opondo a Péricles havia vários anos. Cléon pertencia a uma nova categoria de políticos de Atenas: embora não fossem aristocratas, eram homens ricos, cujas posses provinham do comércio e da manufatura e não da fonte tradicional, a terra. (KAGAN, 2006, p. 99).

Cléon era filho direto da isegoria e da inserção das massas à cidadania por Sólon, um século antes. Sua única arma era a palavra. Tal como Aristóteles (2003, p. 66) descreve, Cléon foi, "com as suas impulsividades, quem mais corrompeu o povo: foi o primeiro a gritar na tribuna, a usar termos insultuosos e a discursar com a roupa cingida".

Como alguém descrito como rude e arrogante, tal como foi Cléon por Aristófanes, poderia chegar a abalar um dos políticos mais importantes e populares de Atenas como Péricles? A justificativa de mera aplicação da isegoria não é o bastante aqui. Para isso, precisamos voltar um pouco no tempo, ainda dentro do século $\mathrm{V}$ a. C. e no mundo Grego Antigo, mas não na Ática.

Na cidade-Estado de Siracusa - curiosamente aliada dos peloponésios, já que fora fundada pelos Coríntios -, na Sicília, no segundo quarto do século V a. C., houve um golpe de Estado que derrubou o tirano Trasíbulo. Assim, na data de 465 a.C., conta a tradição que 0 golpe produzira uma democracia com muitos litígios, especialmente aqueles que buscavam recuperar terras desapropriadas pela tirania anterior. Assim, segundo George Kennedy (1963, p. 26), Córax ou Tisias ambos - como primeiros retores - "começaram a ensinar uma técnica de retórica jurídica para aqueles desacostumados em discursar em público".

No entanto, acredita-se que, muito provavelmente, foi Córax, mestre de Tisias, quem iniciou esses cursos de retórica jurídica para os homens ordinários, a recém-formada "massa", de Siracusa. Tanto que Tisias foi um dos alunos desses cursos, onde Córax ensinava o seu "método tripartite de oratória que auxiliava os cidadãos a falar na assembleia [formado por]: prooemium, agôn e epílogo" (KENNEDY, 1963, p. 59). 0 prooemium é 0 exórdio para atrair a atenção da audiência. 0 agôn incluía uma narração dos fatos e 0 debate deles e, por fim, o epílogo resumia os argumentos e mexia com o público.

Acredita-se, seguindo a tradição contada por Diodorus Siculus, "que a retórica foi trazida para Atenas pelo famoso sofista Górgias, que veio em uma embaixada de Leontini para pedir ajuda ateniense em 427 a. C." (KENNEDY, 1963, p. 26). No entanto, também é dito que Tisias foi professor de muitos retores da Ática como Lísias e Isocrates, sendo o primeiro o mais provável. No entanto, é 
com Tisias que a retórica vira demiourgos, ou seja, criadora da persuasão.

Porém, apesar desse amplo intercâmbio entre Siracusa e Atenas, Górgias vira o ponto de partida ateniense para a retórica. Um exemplo claro para enxergar esse movimento está no diálogo Górgias, de Platão (1871, p. 453), onde 0 personagem Sócrates afirma que fora 0 sofista que definira a retórica como criadora de persuasão.

Ora, mas não podemos considerar essa vinculação gratuita. A Escola Sofística era um tipo prático de filosofia que ensinava as técnicas da vida cívica, da qual a retórica era claramente uma. George Kennedy (1963, p. 62) ressalta que, "mesmo com todo o seu amor pelos sons agradáveis, Górgias não via a retórica como, primariamente, uma forma de entretenimento. 0 objeto da sua oratória era a persuasão".

É famoso o trecho do personagem Górgias que antecede a fala que citamos do personagem Sócrates em Górgias. Nele, Platão (1871, p. 452 ) escreve que 0 sofista questiona "o que é maior que a palavra que persuade os juízes nas cortes ou os senadores no conselho, ou os cidadãos na assembleia ou em qualquer outro encontro político?".

Em um sentido lato do termo, a citação acima do personagem Górgias é uma "pergunta retórica", pois ele já emenda sua conclusão: se você tem o poder de expressar essa palavra, você fará 0 médico seu escravo, 0 treinador 0 seu escravo e 0 ganha-pão daqueles com quem você fala será fonte de tesouros, não para eles, mas para você que é capaz de falar e persuadir a massa (PLAT0, 1871, p. 452).

Apesar de Siracusa ser seu berço, foi no ambiente democrático de Atenas, com o princípio da isegoria, que a retórica ganha a sua dimensão prática prevista. Surgem os manuais de retórica (handbooks) que os grandes mestres retores, tal como Córax, esquematizavam o "falar em público" para qualquer um poder se defender. No fértil ambiente ateniense, tal como coloca George Kennedy (1963, p. 62), o processo democrático fez a demanda por manuais; os filósofos aceleraram 0 desenvolvimento deles.

Os filósofos acima mencionados são os sofistas que, além de escreverem livros, ampliavam 0 ensino através de escolas. Nos séculos V e IV a.C., a educação formal raramente ia além da escola elementar, mas a instrução para discursar publicamente era uma importante parte do ensino dos sofistas, era básico para 0 sistema educacional de Isócrates, e foi ensinado até mesmo por Aristóteles.

Esses manuais e esse sistema de ensino possibilitaram que um membro da "classe média" enriquecida grega, um kakoi dos hoi polloi, tal como Cléon, estivesse à altura para rivalizar com o primeiro cidadão, Péricles, bem nascido em nobreza e em dinheiro. No entanto, "Péricles era uma figura de transição. Pela riqueza e pelo 
nascimento, ele pertencia à velha elite. Só que seus laços não estavam na velha elite ou até mesmo, ao menos publicamente, com a nova elite educada" (OBER, 1990, p. 90).

Ora, "Péricles parece ter ido além de qualquer outro político na promoção, com o pagamento aos jurados, e na aceitação pessoal do poder do povo em determinar o comportamento público de seus líderes" (OBER, 1990, p. 90). Isso é difícil de perceber nos discursos de Péricles transcritos por Tucídides. Assim, "mesmo se considerarmos que as orações no texto de Tucídides são próximas ao que foi discursado, o historiador pode ter desconsiderado (ou apagado) as passagens que pareciam muito demagógicas" (OBER, 1990, p.90-91).

0 motivo de tal postura está nas próprias ideias do historiador Tucídides, filho de Olorus. Nas entrelinhas ou explicitamente, ele, ao longo da História da Guerra do Peloponeso, atribui sentimentos negativos à massa. Primeiramente, ele coloca Péricles como estando acima dela e não por ela. Em um trecho mais próximo do final, que retrata as negociações em Samos em 412-1 a.C., Tucídides retrata um protótipo das massas ignorantes ou volúvel aos tiranos.

"A turba', como Tucídides se refere à assembleia de soldados e marinheiros, 'mesmo estando um tanto aborrecida naquele momento pelo que tinha acontecido, acabou se calando diante da perspectiva de receber dinheiro do Rei'" (KAGAN,
2006, p. 418). Assim, para o historiador, Péricles não era o governante do povo, mas alguém que agia em isolamento magnífico, presciente na compreensão das realidades políticas e autocrata nas suas relações com o demos.

0 interessante era que a oposição elitista $d e$ facto à Péricles tinha as mesmas opiniões do historiador, mas as atribuía ao primeiro cidadão ateniense. 0 político também chamado Tucídides, filho de Melesias, queria tirar Péricles do poder e até mesmo da cidade. Seu "plano político - que incluía a reunião das elites na Assembleia para que eles pudessem votar, importunar e exercer sua autoridade moral sob a massa como um grupo coeso - falhou. Ele foi ostracizado em 443 a.C.; a oposição da elite a Péricles e ao governo das massas desmoronou" (OBER, 1990, p.88-89).

Após a morte de Péricles, e com o desenrolar da Guerra do Peloponeso, o último quarto do século V a.C. demonstra a consolidação do domínio da isegoria e das massas como atores primeiros que, quando não eram atores políticos devido a alguns momentos tirânicos, eram os protagonistas nas instâncias judiciais de Atenas.

É aqui que encontramos o vértice do conceito de massificação completo pela primeira vez. Encontramos o vislumbre de uma ampla participação sociopolítica/cultural das camadas não pertencentes às elites sociais ou políticas, ou culturais, graças à demokratia. 0 âmbito de uma Comunicação Social, mesmo que seja fundada no 
presencial e/ou interpessoal graças à isegoria e à "retórica política, sua filha" (OBER, 1990, p. 87). Além disso, há o contato direto entre as elites mencionadas e as camadas não pertencentes a elas, aliás, a massa é 0 ator que as elites precisam "agradar", pleitear suas vontades. Uma mera insatisfação corria o risco de ser sinônimo de ostracismo.

Assim, não bastava 0 ensino formal e os manuais de retórica. Como um homem - ordinário, de elite ou educado - poderia se defender nos júris populares em um mundo sem advogados? Como ter chances, mesmo sem ter o dom da palavra e tendo o seu uso da força impossibilitado? Surge, assim, o logographos, o logógrafo, profissão equivalente ao redator de discursos atualmente.

Se um litigante não se sentia confiante em fazer o seu próprio discurso ao tribunal do júri composto por cidadãos sorteados de todas as classes sociais e considerados representantes dos hoi polloi, tal como afirmou Ésquines (OBER, 1990, p. 281) -, ele contrataria os serviços do logógrafo, contando o seu caso. Esse testemunho, nas mãos desse mestre retor, transforma-se em uma oração que 0 litigante decoraria e recitaria para a corte.

George Kennedy (1963, p. 127) declara que seria interessante saber quanto o logógrafo atuava como um advogado, procurando por evidências, examinando a lei, dando conselhos na condução do caso, e 0 quanto sua função era simplesmente literária. 0s dois exemplos são referenciados pela historiografia: enquanto Isaeus dava conselhos acerca da lei de heranças, Lísias, comprovadamente, fez apenas o epílogo em duas orações.

É a época dos Dez Oradores Áticos, famosos pelo livro de Pseudoplutarco, A vida dos dez oradores. São eles: Antifonte, Andócides, Lísias, Isócrates, Isaeus, Ésquines, Licurgo, Demóstenes, Hipérides e Dinarco. Nem todos os dez eram logógrafos, mas todos eram grandes oradores, dignos de estudo por observação. Não há grande certeza da extensão do trabalho dos dez, principalmente devido ao fato de que, no final do século V a.C., os oradores não escreviam os discursos que proferiam, com risco de serem identificados com os sofistas e seus manuais, em franca decadência de status cultural.

A importância desses oradores para a retórica está, principalmente, na concepção do texto imerso em um ambiente de comunicação, em emissão não para 0 vento, mas para uma audiência - no caso, a massa - com a qual precisa argumentar sem direito à réplica. Assim, se alguns oradores, como Isaeus e Antifonte, buscavam legitimidade perante à audiência nas leis, outros, como Lísias, buscavam construí-lo no próprio texto. 0 maior legado de Lísias para a oratória foi a ethopoiia:

sua técnica de transportar algo do caráter do emisssor nas orações que ele escreveu para um consumidor declamar. Essa é uma parte de 
reconhecimento prático, a ser feito mais tarde em um nível teórico, que o caráter é um importante meio de prova ou refutação (KENNEDY, 1963, p. 135-6).

No discurso Contra Eratosthenes, tal como George Kennedy (1963, p. 137) analisa,

Lísias amplia o escopo de seu ataque para incluir o nome emocionalmente ampliado de Theramenes. Tudo isso é logicamente irrelevante, mas é retoricamente efetivo em produzir uma impressão de caráter e em conduzir as emoções dos juízes.

Claro que a ethopoiia era duramente criticada pelos oradores que buscavam legitimidade jurídica. Demóstenes (1985, p. 123), em sua Oração da Coroa contra Ésquines, afirma que 0

orador, se é um cidadão honesto, não pode pretender que os juízes, que se apresentem no tribunal para decidir as questões de interesse coletivo, aprovem a ira e a animosidade, nem outras paixões idênticas, que o possam haver inspirado.

Mesmo assim não podemos deixar de afirmar que, nessa querela dos dez oradores, a ethopoiia de Lísias marcou a postura daqueles mais próximos aos hoi polloi. A retórica, enquanto principal meio de Comunicação Social - e único, em um lugar onde não havia jornais, revistas, folhetos ou circulares e a informação era divulgada oralmente -, não buscava mais agradar as massas por joguetes lógicos, verdadeiros ou falaciosos, tal como os entimemas.

Se Cléon era o símbolo da inclusão política da massa, Lísias é a prova da inclusão comunicativa da massa na democracia ateniense. Ele, como estrangeiro, não era um cidadão ateniense e a violência dos seus sentimentos - inclusive na forma de ethopoiia - contra os oligarcas,

tal como expresso em Contra Eratosthenes e Contra Agoratus, é compreensível. A maioria dos outros discursos mostram também uma preferência pelos democratas, mas, em alguns casos, Lísias parece ter concordado em escrever para aqueles, no mínimo, expostos (KENNEDY, 1963, p. 138).

George Kennedy (1963, p. 138) ressalta que "parece possível que Lísias era liberal o bastante para assumir a defesa desses homens tal como um advogado moderno faria. 0 direito de defender a si mesmo era parte da tradição democrática”. A retórica aqui cumpre uma função comunicativa, de dar voz àqueles que não conseguiriam falar em um ambiente de risco.

A agilidade técnica de Lísias em expressar que a defesa não era um ato político de sua parte, mas que recusar um cliente sob essas circuntâncias seria análogo à recusa da parte de um magistrado em ouvir uma defesa (KENNEDY, 1963, p. 138).

A ampliação, via retórica, da esfera comunicativa na democracia grega, no final do século V a.C., produziu mais um âmbito de comunicação popular: o pheme, algo que poderia ser traduzido por rumor. 0 locus de Comunicação Social não estava apenas nas instituições como a Assembleia e o Jurí. As

“aparições públicas 'oficiais' faziam apenas parte da imagem geral de um cidadão proeminente desfrutada pelo populacho. Muito dependia 
do rumor e da fofoca, que eram particularmente importantes em uma sociedade que não tinha mídia noticiosa" (OBER, 1990, p. 148).

Assim, a atividade retórica era literalmente pública. É famosa a frase de Hipérides (apud OBER, 1990, p. 149) que afirma que "até as crianças em idade escolar de Atenas sabiam qual dos oradores havia sido subornado". Hipérides era 0 orador que mais acreditava que existia uma espécie de esfera pública fundada pela retórica. Josiah Ober (1990, p. 150) relata que,

quando Hipérides argumentou que uma defesa legal devia ser feita na vida inteira de um homem, já que nenhum indivíduo na pólis poderia acreditar enganar a 'massa de vocês' (to plèthos to humeteron), ele implica que argumentos baseados no senso comum são justos e democráticos (OBER, 1990, p. 150).

Ora, Hipérides talvez seja um dos primeiros a sintetizar o lema corrente da sabedoria das massas, ou seja, aquele que diz que é fácil enganar poucos, mas impossível manipular muitos. Até mesmo,

Ésquines, que louvou a divindade da pheme, disse que estava trabalhando "quando a massa de cidadãos em sua própria vontade (...) disser que é o caso'” (OBER, 1990, p. 150).

Uma boa imagem do que seria a pheme é descrita por François-Désiré Bancel (1869, p. 51):

Adicione a este instinto de tumulto, a essa necessidade de agitação e de barulho, uma certa frivolidade, uma certa inconstância, 0 sentimento mais vivo e mais delicado dos charmes da linguagem.
A reação do público mostra algo próximo ao broadcasting de hoje, com um pólo de emissão sendo julgado por uma opinião pública que 0 orador quer persuadir, prevendo-a, emocionando-a. Assim, Bancel (1869, p. 51) nos fala para imaginar tal situação enquanto

ondas barulhentas de uma massa inquieta, invejosa, impaciente, blasé, acostumadas às maravilhas do discurso, às vezes dócil aos bons conselhos, aos bons rebeldes, estava aberta à Cléon uma orelha complacente que estava fechada para Nicias (BANCEL, 1869, p. 51).

Dessa forma, a soma de demokratia, isonomia, isegoria, retórica e pheme formou uma protoesfera pública de facto. "Em Atenas, os símbolos-chave foram tanto revelados como gerados através de uma comunicação de mão dupla do discurso público" (OBER, 1990, p. 338).

Essa conclusão de Josiah Ober reside no fato de que a:

comunicação retórica entre massas e elites, expressa através de um crescente vocabulário rico de topoi e imagens, foi um primeiro meio pelo qual o fim estratégico da estabilidade social foi alcançado. Comunicação foi a ferramenta que iguais políticos usaram para exercer sua hegemonia ideológica sobre as elites sociopolíticas (OBER, 1990, p. 338).

Assim, a retórica ateniense foi, mesmo oscilando entre táticas elitistas e igualitárias, a formachave do discurso democrático. Ela ficou no lugar da teoria abstrata da democracia e fez a 
teoria desnecessária para os participantes. Para Josiah Ober, o exemplo ateniense, onde a

tese que as massas controlaram as classes altas através de meios ideológicos também inverte a tradicional concepção marxista de ideologia e levanta a possibilidade que as classes baixas podem obter maiores mudanças na organização da sociedade sem recorrer à luta no campo material (OBER, 1990, p. 339).

No entanto, Ober parece ter congelado a sua análise no quadro que antes pintamos: 0 da fronteira entre século V a. C. e o século IV a. C., onde a retórica realmente instaura a ampla Comunicação Social e uma plena visibilidade das massas. No entanto, essa mesma fronteira temporal e as primeiras décadas do século IV a. C. demonstram uma outra visão acerca das massas e dessa Comunicação Social promovida - e que a promoveu - por elas. É o nascimento da filosofia em seu berço socrático.

\section{Parrhesia}

Para Sócrates e Platão, o par de isegoria não era a retórica, mas sim a parrhesia. Foucault (1983, aula 1) lembra que nessa a tradição

parrhesia e retórica estão em forte oposição; e essa oposição aparece muito claramente em Górgias, por exemplo, onde a palavra parrhesia é mencionada. 0 discurso longo e contínuo é um instrumento retórico ou sofístico e o diálogo através de perguntas e respostas é típico da parrhesia (FOUCAULT, 1983, aula 1).
Assim, apenas o diálogo cumpriria a parrhesia, que pode ser definida como "liberdade de expressão". No entanto, "aquele que usa a parrhesia, o parrhesiastes, é alguém que diz tudo que tem na mente (...). Na parrhesia, 0 orador precisar dar um completo e exato relato do que pensa para que a audiência seja capaz de compreender exatamente 0 que ele pensa" (FOUCAULT, 1983, aula 1).

Não estamos falando mais de ethopoiia, que pode ser artificialmente construída tal como um personagem. Tal como Foucault (1983, aula 1) analisa, a oposição entre parrhesia e retórica também está no Fedro, de Platão, onde o principal problema não é sobre a natureza da oposição entre discurso e escrita, mas sobre a diferença entre 0 logos capaz de dizer a verdade e o logos que não é capaz de tal veracidade.

Dessa forma, é como se a retórica não devesse ocupar o locus comunicativo adquirido ao longo do século V a. C., já que sua ocupante de jure é a parrhesia. Michel Foucault (1983, aula 1) chega, até mesmo, a dizer que a "parrhesia era uma diretriz para a democracia assim como uma atitude ética e pessoal do bom cidadão".

Surge assim, a visão de que a democracia ateniense era uma constituição (politeia) onde as pessoas gozavam de demokratia, isegoria (o direito igual de fala), isonomia (a igual participação de todos os cidadãos no exercício do poder) e parrhesia. Parrhesia, que é requisito 
para o discurso público, toma lugar entre os cidadãos como indivíduos assim como entre cidadãos em assembleia (FOUCAULT, 1983, aula 1).

Devemos ressaltar aqui a questão da parrhesia como atitude pessoal - 0 sujeito do enunciado é a sua própria opinião - contra a retórica que se desenvolve, como atitude comunal, para ser aceita pelo outro, pela audiência. Além disso, a parrhesia é uma atitude individual - onde 0 orador deve falar a sua verdade - contra a retórica, atitude coletiva, onde 0 orador não pode mentir porque os muitos, hoi polloi, sabem a verdade.

\section{Desvalorização plato-aristotélica}

Assim, o século IV a. C. marca uma desvalorização da massa e da sua sabedoria para ressaltar a sabedoria do indivíduo em diálogo com outro indivíduo, ambos bons cidadãos. Platão, em $A$ República, discute o governo da cidade justa, sendo reconstruída a ordem dos guardiões e proposta a figura do rei-filósofo. A democracia, nessa linha de raciocínio, é o governo onde a igualdade reside

entre antropologia e bestiário. Também essa igualização e liberdade indeterminadas, atingindo a máxima amplitude, transformam-se em seu reverso, na servidão, na tirania e no mais infeliz e miserável dos personagens, o tirano, motores destrutivos da cidade devastada por completa inversão de valores e pela injustiça (FRANC0, 2006, p. 20).

A crítica que $A$ República faz da democracia está justamente na ampla participação dos hoi polloi, produzindo igualdade. Ora, tal como 0 auge da explicação platônica declara, a democracia é "uma bela forma de governo, anárquica e variegada, que confere uma espécie de igualdade tanto ao que é desigual como ao que é igual" (PLATÃo, 2006, p. 322).

Para J. Guinsburg (apud PLATÃ0, 2006, p. 322), baseando sua leitura de A República no diálogo Leis, este é um princípio que norteia a crítica platônica da democracia: os homens são naturalmente desiguais (...). Aquele que merece mais deve ter mais, enquanto aquele que merece menos, deve ter menos: essa é a medida que não há na democracia.

A liberdade excessiva da democracia transformase em tirania graças ao apoio do povo, garantindo obediência cega ao tirano. A ignorância faz a massa ser 0 protetor daquele que é seu defensor, tal como descreve Platão (2006, p.333) no termo "petição do tirano".

A retórica - como adulação da alma, tal como é retratada em Górgias - é um dos meios que levam ao cumprimento do destino patológico da democracia, simplesmente porque ela é irracional, visando apenas o prazer das palavras.

0 âmbito de aplicação da retórica é a justiça, e seu escopo não é instruir o público nos tribunais acerca do que é verdadeiramente justo ou injusto, mas simplesmente fazê-lo crer numa imagem de justiça que corrobore uma das partes envolvidas no processo litigioso (GUINSBURG apud PLATÃo, 2006, p. 267). 
Assim, Guinsburg (apud PLATÃo, 2006, p. 268) ressalta que, no pensamento platônico,

a retórica, então, apresenta-se como a parte da adulação que se inflitra na justiça e finge ser a própria justiça, não a sendo (...). Platão critica duramente a retórica pelo fato de ela servir como instrumento de justificação e legitimação da injustiça.

Injustiça essa que podemos identificar, no pensamento platônico, na questão democrática de forçar uma igualdade aos desiguais.

Mesmo em Fedro, obra central sobre debate da linguagem, o retrato platônico da retórica "parece basicamente a questão de usar argumentos $a d$ hominem e é reminiscente da 'mentira nobre' de A República, onde o ouvinte de menor inteligência sofre uma lavagem cerebral para aceitar a verdade por um onisciente filósofo-orador" (KENNEDY, 1963, p. 79). Não havia a necessidade de veracidade pois, nessa linha de raciocínio, muitas pessoas eram capazes de serem persuadidas apenas por mentiras atrativas.

Ao contrário da ambivalência de significado que a massa possuía no século V a.C. - onde pendia, até mesmo, mais para uma visão positiva acerca de sua participação no que podemos chamar de diálogo público -, agora os hoi polloi são frutos da ignorância e da legitimação da injustiça no platonismo do século IV antes da era Cristã. Essa convivência de significados acerca da massa e da massificação só retornaria com Aristóteles, discípulo de Platão, que tinha, provavelmente, quatro anos de idade na época da elaboração de $A$ República.

Aristóteles não apenas destinava uma ambivalência à massa, mas também à retórica que, mesmo sendo amplamente criticada por Platão, obteve a autorização do último para que o próprio Aristóteles a ensinasse na Academia. Talvez a maior referência que temos da retórica grega é a sua obra, Retórica. No entanto, tal como George Kennedy (1963, p. 82) aponta, o livro de Aristóteles apresenta diversas inconsistências aparentes. Por exemplo, 0 começo do primeiro livro ataca os manuais, que se preocupam em como provocar emoções e catalogar as partes da oração. Só que no livro dois, o próprio Aristóteles discute 0 apelo emocional e no livro três ele, também, cataloga as partes da oração.

Além de fornecer uma primeira teorização da Retórica, Aristóteles trabalha a questão sociocomunicativa por ela imposta. Ele acredita

que, em presença de certos ouvintes, mesmo que estejamos de posse da mais rigorosa ciência, seria difícil extrair destas provas convincentes para nossos discursos (ARISTÓTELES, 2005a, p. 31).

Dessa forma, a retórica é útil, servindo em situações de interlocução, pois, como bem coloca Aristóteles (2005a, p. 31), o discurso

inspirado pela ciência pertence ao ensino; discurso impossível aqui, dada a necessidade de tirar de argumentos comuns as provas e raciocínios, como dissemos igualmente nos Tópicos, ao falarmos da maneira de nos dirigirmos às multidões. 
Ora, aqui Aristóteles faz referência aos Tópicos, onde ele afirmara categoricamente que, "na argumentação dialética, o silogismo deve ser usado mais contra os dialéticos do que contra a multidão; pelo contrário, 0 raciocínio indutivo deve, de preferência, ser utilizado contra a multidão" (ARISTÓTELES, 2005c, p. 522).

Nesse momento, encontramos uma referência ao que o Aristóteles (2005c, p. 361) dissera no início:

A indução é mais convincente e mais clara, além de ser mais facilmente apreendida pela percepção sensorial, sendo compartilhada pela maioria das pessoas; o silogismo, entretanto, detém maior vigor racional e é mais eficaz contra os contestadores.

A análise lógica de Aristóteles referenda algo que percebemos na análise sociocomunicativa da Grécia Antiga. Apesar da retórica, em um jogo de fundação-auxílio, funcionar dentro de um espaço público, o seu sucesso está exatamente no fato de que a isegoria vigente é dos pólos centrais de emissão, tal como 0 modelo broadcasting, onde um exerce sua igualdade de fala para muitos. Aqui o diálogo é indireto. Seria algo próximo do contemporâneo hearts and minds - onde devemos destacar sua proximidade conceitual com os termos gregos pathos e logos/ethos - que provoca mais um julgamento, via aprovação ou desaprovação, do que um diálogo com a opinião pública.

A tarefa da retórica é persuadir tanto a inteligência como a ignorância do seu auditório.
Consiste em versar as questões sobre as quais deliberamos, e das quais ainda não possuímos artes; e isto perante um auditório incapaz de ver claro através de numerosas preposições e de raciocinar sobre noções deduzidas de longe (ARISTÓTELES, 2005a, p. 35).

0 interessante é que Aristóteles, em sua Política, trabalha tanto o conceito de "tirania das massas" como o de "sabedoria das massas". Em uma República - ou em sua corruptela, a Democracia -, Aristóteles (1960, p. 122) indica que "o soberano não é um juiz, um senador ou um membro da assembleia, mas 0 tribunal, 0 senado e o povo". Assim, o poder não é individual, pois "é justo que a multidão tenha um poder maior, visto que é ela que constitui o povo, o senado e 0 tribunal" (ARISTÓTELES, 1960, p. 122).

Além disso, Aristóteles (1960, p. 136) utiliza a metáfora de que "um banquete ao qual cada um traz a sua parte é mais belo e menos simples que aquele que é custeado por uma só pessoa" para justificar a coletivização do poder político. Além disso, ele também indica que

a multidão é melhor juiz que um só indivíduo, qualquer que ele seja. A multidão possui ainda a vantagem de ser mais incorruptível. A água se adultera tanto menos facilmente quanto maior for a sua quantidade; do mesmo modo a multidão é mais difícil de corromper que o pequeno número (ARISTÓTELES, 1960, p. 136).

São nessas bases que se assentam a ideia de uma "sabedoria das massas" e uma divisão social do poder onde os membros da assembleia grega eram sorteados entre todos os cidadãos, não havendo 
nenhuma eleição. Só que, como já vimos, esse pensamento não era unâmine entre os gregos, principalmente na fronteira do século $\mathrm{V}$ a.C. e IV a.C. mencionada aqui. 0 próprio Aristóteles indica a possibilidade das massas se apresentarem enquanto tiranas.

Ao analisar a forma política da tirania, há afirmação de que se "a realeza foi estabelecida para preservar a classe abastada dos atentados da multidão (...). 0 tirano, ao contrário, surge do seio do povo e da multidão" (ARISTÓTELES, 1960, p. 331). Assim, 0 tirano é aquele que manipula essa multidão $0^{5} \mathrm{em}$ sua estupidez cega, mas - em um prenúncio do populismo, que seria "inventado" com os populares na Roma Antiga - não pode "fazer despesas e liberalidades que irritem a multidão quando ela percebe que 0 fruto dos seus trabalhos, das suas fadigas e das suas privações é roubado por ser prodigalizado a cortesãs, a estrangeiros e a artistas" (ARISTÓTELES, 1960, p. 344).

\section{Considerações finais}

Ora, a análise aristotélica não é o ponto final da questão, mas apenas um início.

No período entre a morte de Aristóteles à fundação do Império Romano, a teoria da retórica que foi amplamente desenvolvida no século IV a.C. foi extensivamente aumentada em um sistema aumentado. Esse sistema, junto com exercícios práticos, ganhou um papel central, primeiramente na educação secundária, depois na avançada (KENNEDY, 1963, p. 264).

Pouco se sabe da retórica no Helenismo, normalmente demarcado pelo período entre 323 a.C. (morte de Alexandre, 0 Grande) e anexação das ilhas gregas por Roma em 147 a.C., próximo à mudanças bem documentadas na República Romana. Sabemos, através de Cícero e de Quintiliano, de algumas informações soltas sobre alguns retores.

Percebemos, através do relato de Cícero sobre Demétrio de Falero, que a ethopoiia continuou em grande voga ao longo da retórica dos séculos seguintes, tanto com aqueles que estavam ao lado da massa, que seriam chamados em Roma de populares, como aqueles que estavam ao lado dos melhores, tal como Cícero se posicionava, chamados de optimates. 0 começo desse embate acerca da massa, através da Comunicação Social, começa em Roma bastante próximo do fim do Helenismo, com a eleição de Tibério Graco ao cargo de tribuno da plebe em 133 a.C., iniciando uma nova visão da massificação, muito próxima daquela ambivalência teorizada por Aristóteles em sua Política.

Dessa forma, indo da retórica para os governantes e aos filósofos, foi possível demarcar uma préhistória do conceito de massificação que se

Essa manipulação não é feita apenas pela retórica. Averroes (1977b, p. 84), ao comentar sobre a Poética e a questão nela apresentada sobre os discursos poéticos, afirma que "Aristóteles chegou a opinião de que essa arte como altamente útel porque pelos seus meios as almas da multidão poderiam ser movidas a acreditar ou não acreditar em certa coisa e para fazer ou abandonar certa coisa". 
coloca no vértice dos três elementos básicos para caracterizar esse conceito como tal: (1) 0 vislumbre de uma ampla participação sociopolítica/cultural das camadas não pertencentes às elites sociais ou políticas ou culturais; (2) 0 âmbito de uma Comunicação Social, mesmo que seja fundada no presencial e/ou interpessoal; e (3) no contato direto entre as elites mencionadas e as camadas não pertencentes a elas. Tudo isso antes da demarcação tradicional posta em Tocqueville, e mesmo da reflexão de Martín-Barbero que indica o início em Maquiavel. É 0 indicativo da reflexão comunicacional, através da presença de um conceito, já na etapa primeira do pensamento ocidental.

\section{Referências}

ARISTÓTELES. A Política. São Paulo: Atena, 1963.

ARISTÓTELES. Constituição dos Atenienses. Lisboa: Caloustre Gulbenkian, 2003.

ARISTÓTELES. Arte Retórica e Arte Poética. Rio de Janeiro: Ediouro, 2005a.

ARISTÓTELES. Analíticos Anteriores. In: ARISTÓTELES. Órganon. Bauru: Edipro, 2005b.

ARISTÓTELES. Tópicos. In: ARISTÓTELES. Órganon. Bauru: Edipro, 2005c.

AVERROES. "Short Commentary on Aristotle's

'Rhetoric'”. In. AVERROES. Three Shorts

Commentaries on Aristotle's "Topics", "Rhetoric", and "Poetics". Albany: SUNY Press, 1977a.

AVERROES. "Short Commentary on Aristotle's

'Poetics'”. In. AVERROES. Three Shorts

Commentaries on Aristotle's "Topics", "Rhetoric", and "Poetics". Albany: SUNY Press, 1977b.
BANCEL, F-D. Les Révolutions de la Parole. Paris: Degorce-Cadot, 1869.

DEMÓSTENES. A Oração da Coroa. Rio de Janeiro: Ediouro, 1985.

FOUCAULT, M. Discourse and Truth: the Problematization of Parrhesia. Transcrição de Joseph Pearson do seminário ministrado na University of California em outubro-novembro/1983. Berkeley: Foucault.Info, 1983. Disponível em: http://www. foucault.info/documents/parrhesia/.

FRANCO, M. S. C. "Introdução". In: PLATÃO. A República (trad. J. Guinsburg). São Paulo: Perspectiva, 2006.

KAGAN, D. A Guerra do Peloponeso. Rio de Janeiro: Record, 2006.

KENNEDY, G. The art of persuasion in Greece.

Princeton: PUP, 1963.

MARTÍN-BARBERO, J. Dos meios às mediações. Rio de Janeiro: Ed. UFRJ, 2006.

OBER, J. Mass and Elite in Democratic Athens. Princeton: Princeton, 1990.

PEREIRA, I. Dicionário Grego-Português e PortuguêsGrego. Porto: Apostolado da Imprensa, 1951.

PLATÃO. A República (trad. J. Guinsburg). São Paulo: Perspectiva, 2006.

PLATO. The Dialogues of Plato. London: Bell \& Daldy, 1871.

SWINGEWOOD, A. The Myth of Mass Culture. London: Macmillan, 1977.

TOCQUEVILLE, A. de. Democracy in America. Chicago: UOC Press, 2002.

THUCYDIDES. History of the Peloponnesian War (trad. Richard Crawley). Mineola: Dover, 2004.

VENANCIO, R. D. 0. Massificação e Jornalismo. Dissertação de Mestrado. São Paulo: PPGCOM-ECAUSP, 2010 


\begin{tabular}{|c|c|}
\hline $\begin{array}{l}\text { Protomassifications: The beginning } \\
\text { of the communicational concept of } \\
\text { massification in Ancient Greece }\end{array}$ & $\begin{array}{l}\text { Protomasificaciones: El principio } \\
\text { del concepto comunicacional de } \\
\text { masificación en la Grecia antigua }\end{array}$ \\
\hline $\begin{array}{l}\text { Abstract } \\
\text { This article want to identify the start of the } \\
\text { massification concept in Ancient Greece. The } \\
\text { epistemological-historical investigation here put } \\
\text { seeks to understand how concepts such as hoi } \\
\text { polloi and isegoria in joints with rhetoric and } \\
\text { parrhesia notions, can be marked as the beginning } \\
\text { of a formulation of this key concept within the } \\
\text { Communication Sciences, anticipating the classic } \\
\text { formulation of massification posed by Alexis de } \\
\text { Tocqueville. } \\
\text { Keywords } \\
\text { Epistemology. Hoi polloi. Massification }\end{array}$ & $\begin{array}{l}\text { Resumen } \\
\text { En este artículo se quiere identificar el inicio del } \\
\text { concepto de masificación en la antigua Grecia. La } \\
\text { investigación histórica-epistemológica aquí poner } \\
\text { busca entender cómo los conceptos tales como hoi } \\
\text { polloi y isegoria en las articulaciones con la retórica } \\
\text { y la parrhesia nociones, se pueden marcar como } \\
\text { el comienzo de una formulación de este concepto } \\
\text { clave dentro de las Ciencias de la Comunicación, } \\
\text { anticipándose a la formulación clásica de } \\
\text { masificación planteado por Alexis de Tocqueville. } \\
\text { Palabras clave } \\
\text { Epistemología. Hoi polloi. Masificación }\end{array}$ \\
\hline
\end{tabular}




\section{Expediente}

A revista E-Compós é a publicação científica em formato eletrônico da Associação Nacional dos Programas de Pós-Graduação em Comunicação (Compós). Lançada em 2004, tem como principal finalidade difundir a produção acadêmica de pesquisadores da área de Comunicação, inseridos em instituições do Brasil e do exterior.

\section{E-COMPÓS I www.e-compos.org.br I E-ISSN 1808-2599}

Revista da Associação Nacional dos Programas de Pós-Graduação em Comunicação. Brasília, v.20, n.2, maio/ago. 2017. A identificação das edições, a partir de 2008, passa a ser volume anual com três números. Indexada por Latindex I www.latindex.unam.mx

\section{CONSELHO EDITORIAL}

Alda Cristina Silva da Costa, Universidade Federal do Pará, Brasil Alfredo Luiz Paes de Oliveira Suppia, Universidade Estadual de Campinas, Brasil Álvaro Larangeira, Universidade Tuiuti do Paraná, Brasil Ana Carolina D. Escosteguy, Pontifícia Universidade Católica do Rio Grande do Sul, Brasil Ana Regina Barros Rego Leal, Universidade Federal do Piauí, Brasil Ana Carolina Rocha Pessôa Temer, Universidade Federal de Goiás, Brasil Andrea França, Pontifícia Universidade Católica do Rio de Janeiro, Brasil André Luiz Martins Lemos, Universidade Federal da Bahia, Brasil Angela Cristina Salgueiro Marques, Faculdade Cásper Libero, Brasil Ângela Freire Prysthon, Universidade Federal de Pernambuco, Brasil Antonio Carlos Hohlfeldt, Pontifícia Universidade Católica do Rio Grande do Sul, Brasil Arthur Ituassu, Pontifícia Universidade Católica do Rio de Janeiro, Brasil Bruno Campanella, Universidade Federal Fluminense, Brasil Cláudio Novaes Pinto Coelho, Faculdade Cásper Líbero, Brasil Carlos Eduardo Franciscato, Universidade Federal de Sergipe, Brasil Denise Tavares da Silva, Universidade Federal Fluminense, Brasil Eduardo Vicente, Universidade de São Paulo, Brasil Eliza Bachega Casadei, Escola Superior de Propaganda e Marketing - SP, Brasil Elizabeth Nicolau Saad Corrêa, Universidade de São Paulo, Brasil Erick Felinto de Oliveira, Universidade do Estado do Rio de Janeiro, Brasil Erly Vieira Júnior, Universidade Federal do Espírito Santo, Brasil Francisco de Assis, FIAM-FAAM Centro Universitário, Brasil Francisco Elinaldo Teixeira, Universidade Estadual de Campinas, Brasil Frederico de Mello Brandão Tavares, Universidade Federal de Ouro Preto, Brasil Gabriela Reinaldo, Universidade Federal do Ceará, Brasil

Gilson Vieira Monteiro, Universidade Federal do Amazonas, Brasil Gustavo Daudt Fischer, Universidade do Vale do Rio dos Sinos, Brasi Itania Maria Mota Gomes, Universidade Federal da Bahia, Brasil Jiani Adriana Bonin, Universidade do Vale do Rio dos Sinos, Brasil José Afonso da Silva Junior, Universidade Federal de Pernambuco, Brasil José Luiz Aidar Prado, Pontifícia Universidade Católica de São Paulo, Brasi
Juçara Gorski Brittes, Universidade Federal de Ouro Preto, Brasil Juliana Freire Gutmann, Universidade Federal da Bahia, Brasil Laura Loguercio Cánepa, Universidade Anhembi Morumbi, Brasil Letícia Cantarela Matheus, Universidade do Estado do Rio de Janeiro, Brasil Liziane Soares Guazina, Universidade de Brasília, Brasil Luíza Mônica Assis da Silva, Universidade Católica de Brasília, Brasil Maria Ataide Malcher, Universidade Federal do Pará, Brasil Maria Elisabete Antonioli, Escola Superior de Propaganda e Marketing - SP, Brasil Maria das Graças Pinto Coelho, Universidade Federal do Rio Grande do Norte, Brasil Marcel Vieira Barreto Silva, Universidade Federal da Paraiba, Brasil Marcia Tondato, Escola Superior de Propaganda e Marketing, Brasil Marli Santos, Universidade Metodista de São Paulo, Brasil Márcio Souza Gonçalves, Universidade do Estado do Rio de Janeiro, Brasil Mauricio Mario Monteiro, Universidade Anhembi Morumbi, Brasil Mauricio Ribeiro da Silva, Universidade Paulista, Brasil Mauro de Souza Ventura, Universidade Estadual Paulista, Brasil Mayka Castellano, Universidade Federal Fluminense, Brasi Micael Maiolino Herschmann, Universidade Federal do Rio de Janeiro, Brasil Mozahir Salomão Bruck, Pontifícia Universidade Católica de Minas Gerais, Brasil Nísia Martins Rosario, Universidade Federal do Rio Grande do Sul, Brasil Potiguara Mendes Silveira Jr, Universidade Federal de Juiz de Fora, Brasil Rafael Grohmann, FIAM-FAAM - Centro Universitário, Brasil Raquel Ritter Longhi, Universidade Federal de Santa Catarina, Brasil Regiane Regina Ribeiro, Universidade Federal do Paraná, Brasil Roberto Elísio dos Santos, Universidade Municipal de São Caetano do Sul, Brasil Rodolfo Rorato Londero, Universidade Estadual de Londrina, Brasil Sérgio Luiz Gadini, Universidade Estadual de Ponta Grossa, Brasil Simone Maria Andrade Pereira de Sá, Universidade Federal Fluminense, Brasil Simone Maria Rocha, Universidade Federal de Minas Gerais, Brasil Suzana Reck Miranda, Universidade Federal de São Carlos, Brasil Tarcyanie Cajueiro Santos, Universidade de Sorocaba, Brasil Tatiana Oliveira Siciliano, Pontifícia Universidade Católica do Rio de Janeiro, Brasil Veneza Mayora Ronsini, Universidade Federal de Santa Maria, Brasil

\section{CONSELHO CIENTÍFICO}

Cristiane Freitas Gutfreind, Pontifícia Universidade Católica do Rio Grande do Sul, Brasil | Eduardo Antônio de Jesus, Universidade Federal de Minhas Gerais, Brasil | Eduardo Morettin, Universidade de São Paulo, Brasil I Irene de Araújo Machado, Universidade de São Paulo, Brasil I Miriam de Souza Rossini, Universidade Federal do Rio Grande do Sul, Brasil

\section{COMISSÃO EDITORIAL}

Eduardo Antonio de Jesus, Universidade Federal de Minas Gerais, Brasil I Igor Pinto Sacramento, Universidade Federal do Rio de Janeiro, Brasil I Kelly Cristina de Souza Prudencio, Universidade Federal do Paraná, Brasil I Osmar Gonçalves dos Reis Filho, Universidade Federal do Ceará, Brasil

\section{CONSULTORES AD HOC}

Cesar Augusto Baio Santos, Universidade Federal do Ceará, Brasil I Lilian França Universidade Federal de Sergipe, Brasil I Maria Aparecida Baccega, Escola Superior de Propaganda e Marketing, Brasil I Márcia Benetti, Universidade Federal do Rio Grande do Sul, Brasil I Miguel Serpa Pereira, Pontifícia Universidade Católica do Rio de Janeiro, Brasil | Renato Essenfelder, Escola Superior de Propaganda e Marketing, Brasil

\section{EQUIPE TÉCNICA}

ASSISTENTE EDITORIAL Márcio Zanetti Negrini | REVISÃO DE TEXTOS Melina Santos | EDITORAÇÃO ELETRÔNICA Roka Estúdio I IMAGEM DE CAPA Silas de Paula

COMPÓS I www.compos.org.br

Associação Nacional dos Programas de Pós-Graduação em Comunicação

Presidente

Marco Roxo

Programa de Pós-Graduação em Comunicação - UFF marcos-roxo@uol.com.br

Vice-Presidente Isaltina Gomes Programa de Pós-Graduação em Comunicação - UFPE isaltina@gmail.com

Secretária-Geral

Gisela Castro

Programa de Pós-Graduação em Comunicação e Práticas de Consumo - ESPM castro.gisela@gmail.com

CONTATO I revistaecompos@gmail.com 